\title{
PENGEMBANGAN APLIKASI KOMUNIKASI PADA PERANGKAT ANDROID BERBASIS JARINGAN MANET UNTUK PENANGGULANGAN DAERAH BENCANA
}

\author{
Ahmad Sabiq \\ Program Studi Teknik Informatika, Fakultas Teknologi Informasi, Universitas YARSI, Jakarta, Indonesia \\ E-mail: ahmad.sabiq@yarsi.ac.id
}

\begin{abstract}
A communication system without network supporting is needed to resolve the paralyzed network and communication infrastucture caused by natural disaster. MANET (Mobile AdHoc Network) is a network consisting of several mobile devices that communicates through wireless network without router. Mobile devices are not only used for voice and data transfer, but also as a router. This research develops a mobile application based on MANET that can communicate without network infrastructure. It can be used when the natural disaster damages the network infrastructure. The testing result shows the application, that runs under android platform, can communicate well in MANET network.
\end{abstract}

Key Word: Ad-hoc network, manet, disaster recovery

\begin{abstract}
Abstrak
Pada kondisi bencana alam yang menyebabkan infrastruktur jaringan dan komunikasi lumpuh, dibutuhkan sebuah sistem komunikasi yang mampu digunakan tanpa adanya infrastruktur jaringan. Jaringan MANET (Mobile Ad-Hoc Network) merupakan jaringan yang terdiri dari beberapa perangkat bergerak yang berkomunikasi melalui jaringan nirkabel tanpa router yang secara khusus disediakan, sehingga semua perangkat bergerak yang digunakan selain berfungsi sebagai alat untuk komunikasi dan pertukaran data, juga berfungsi sebagai perantara komunikasi atau router. Pada penelitian ini, dibuat sebuah aplikasi untuk melakukan komunikasi pada perangkat android melalui jaringan tanpa infrastruktur berbasis MANET yang dapat digunakan pada penanggulangan bencana yang mengakibatkan lumpuhnya sarana jaringan dan komunikasi. Dari hasil pengujian, aplikasi yang telah dibuat dapat digunakan untuk berkomunikasi pada perangkat android berbasis jaringan MANET.
\end{abstract}

Kata Kunci: Jaringan ad-hoc, manet, penanggulangan bencana

\section{Pendahuluan}

Bencana alam murupakan salah satu kejadian yang dapat terjadi kapan dan di mana saja, terkadang bencana alam juga dapat meruntuhkan segala sarana dan prasarana di suatu wilayah. Secara geologi indonesia merupakan daerah yang rawan dengan bencana alam (HPLI 2012). Pada proses penanggulangan bencana, umumnya diterjunkan tim penanggulangan bencana yang saling berkoordinasi melalui saluran komunikasi. Pada situasi bencana alam yang menyebabkan infrastruktur jaringan dan komunikasi lumpuh, dibutuhkan sebuah sistem komunikasi yang mampu digunakan tanpa adanya infrastruktur jaringan.

Jaringan ad-hoc multi-hop nirkabel atau $A d$ - hoc wireless multi-hop networks (AHWMNs) merupakan suatu jaringan tanpa infrastruktur yang terdiri dari beberapa perangkat komunikasi nirkabel yang dapat mengirimkan data dan atau menerima data dari perangkat lain serta memiliki kemampuan untuk melakukan routing dan meneruskan paket data dari satu perangkat ke perangkat yang lainnya. Salah satu jenis tipe jaringan ad-hoc adalah jaringan MANET, yang terdiri dari beberapa perangkat bergerak yang berkomunikasi melalui jaringan nirkabel. Pada jaringan MANET tidak terdapat router yang secara khusus disediakan, sehingga semua perangkat bergerak yang digunakan selain berfungsi sebagai alat untuk komunikasi dan pertukaran data, juga berfungsi sebagai perantara 
komunikasi atau router.

Pada penelitian ini, dikembangkan sebuah aplikasi untuk melakukan komunikasi pada perangkat android melalui jaringan tanpa infrastruktur berbasis MANET yang dapat digunakan pada penanggulangan bencana yang mengakibatkan lumpuhnya sarana jaringan dan komunikasi.

\subsection{Jaringan Ad-hoc Multi-hop Nirkabel}

Jaringan ad-hoc multi-hop nirkabel atau Adhoc wireless multi-hop networks (AHWMNs) merupakan sebuah jaringan komunikasi yang terdiri dari sekumpulan node tanpa kabel yang masing-masing node memiliki kemampuan untuk melakukan routing dan meneruskan paket data menuju node yang lain dengan satu atau beberapa langkah dengan melewati beberapa node yang lain.

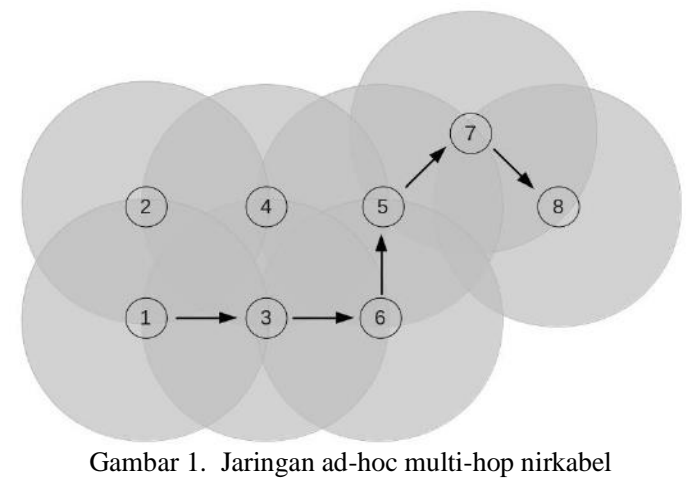

\subsection{Mobile Ad-hoc Network (MANET)}

Mobile Adhoc Network (MANET) atau jaringan ad-hoc bergerak merupakan jaringan yang terdiri dari sekumpulan perangkat bergerak yang dapat melakukan komunikasi satu dengan yang lainnya melalui jaringan tanpa kabel (Royer \& Toh 1999). Setiap perangkat yang biasanya disebut node pada jaringan ini dilengkapi dengan antenna omni directional. Setiap node dapat berfungsi sebagai ujung komunikasi data, dan sebagai router yang dapat meneruskan paket data satu sama lainnya dengan beberapa langkah melewati node yang lainya.

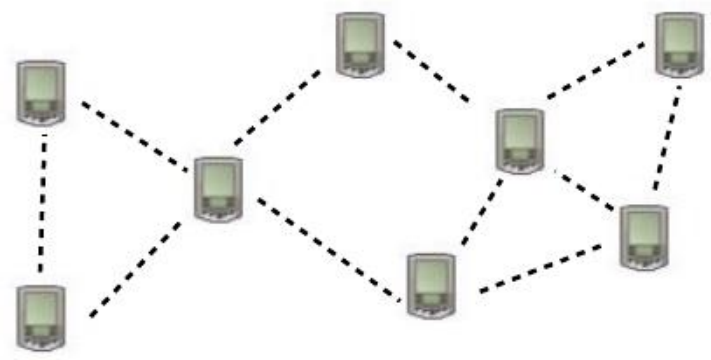

Gambar 2. Jaringan MANET

Pada umumnya MANET bersifat sementara dan tidak memiliki insfrastruktur yang tetap. Jaringan ini dapat terbentuk dari sekelompok pengguna perangkat yang menggunakan wifi seperti laptop, ponsel atau sejenisnya yang bergerak pada area tertentu sehingga membentuk sebuah jaringan yang dinamis di antara mereka. Gambar 2 merupakan contoh dari jaringan Mobile Ad-hoc yang terbentuk dari beberapa perangkat ponsel dan laptop, garis putus-putus pada gambar tersebut menunjukkan hubungan yang dapat dilakukan oleh beberapa perangkat tersebut secara nirkabel.

\subsection{Komunikasi pada Perangkat Bergerak Berbasis Jaringan MANET}

MANET merupakan jenis dari Jaringan Adhoc Multihop Nirkabel yang pertama kali diteliti, yaitu dengan dipublikasikannya algoritma routing Destination-Sequenced Distance-Vector (DSDV) pada tahun 1994 (Perkins \& Bhagwat 1994), ide dasar penggunaan jaringan ini berasal dari penelitian jaringan radio paket DARPA (Tornow 1987).

Penelitian penggunaan jaringan ad-hoc untuk komunikasi bergerak secara simulasi dilakukan untuk mengetahui performa jaringan dengan menggunakan beberapa algoitma routing yaitu AODV (Ad-hoc On-Demand Distance Vector) (Perkins \& Royer 1999), DSDV maupun algoritma baru seperti anthocnet (Ducatelle 2007) serta melakukan optimasi algoritma routing yang sudah ada dengan menggunakan beberapa skenario seperti di perkantoran, rumah sakit, daerah urban, tanggap darurat bencana dan lainnya yang dapat diimplementasikan di dunia nyata (Ducatelle, Di Caro \& Gambardella 2010).

Pengembagan aplikasi komunikasi berbasis manet secara nyata sendiri mulai beragam, baik yang dapat digunakan secara umum ataupun yang dibuat untuk keperluan khusus seperti pada penanggulangan dampak bencana (Catarci et al. 2008). Sebuah aplikasi pengiriman pesan dari handphone berbasis MidletJava dengan teknologi 
manet juga pernah dikembangkan menggunakan koneksi bluetooth (Muliawati, Nadhori \& Setiowati, 2011).

\subsection{MANET pada perangkat android}

Dalam membangun komunikasi berbasis manet dibutuhkan beberapa modul untuk melakukan algoritma routing, manajemen koneksi, transfer data dan keamanan yang masingmasing bekerjasama agar jaringan MANET dapat berjalan.

ALLjoyn merupakan proyek opensource yang menyediakan framework universal untuk android, iOS, windows, Mac OS dan Linux, yang memungkinkan perangkat lunak pada beberapa perangkat yang berbeda dapat berinteraksi pada jaringan dinamis tunggal (bluAir 2011). Koneksi yang digunakan pada Alljoyn menggunakan koneksi bluetooth dan Wifi dasar. Wifi dasar sendiri pada dasarnya tidak dapat digunakan untuk membuat MANET karena membutuhkan akses point. Sedangkan penggunaan bluetooth sendiri hanya memiliki jangkauan 100 meter untuk kelas 1 (umumnya stabil pada 20-30 meter) dan untuk kelas 2 memiliki jangkauan 30 meter (umumnya stabil pada 5-10 meter). Jangkauan bluetooth yang terlalu pendek ini membuat bluetooth sulit digunakan untuk jaringan MANET.

Serval Mesh adalah app android yang menjadi bagian dari proyek yang lebih besar dengan tujuan menyediakan komunikasi di daerah-daerah yang terkena bencana dan keadaan darurat (The Serval Project, 2013). Komunikasi yang dilakukan pada proyek ini terdiri dari dua komponen, yaitu 'batphone' dan servalDNA. 'Batphone' merupakan antarmuka pengguna dan aplikasi pada perangkat android yang dibangun menggunakan SDK Android, sedangkan servalDNA adalah jaringan inti yang menggunakan perangkat khusus dengan daemon yang ditulis dalam GNU $\mathrm{C}$ dan dibangun menggunakan NDK Android. Meskipun proyek serval mesh ini bersifat opensource, namun tidak ada dokumentasi pengembangan yang tersedia. Sehingga menyulitkan membangun aplikasi kustom yang memanfaatkan servalDNA.

Manet Manager merupakan aplikasi pada android yang memungkinkan pengembang lain menerapkan dan mengelola sebuah MANET berbasis android (Stoker 2012). Manet Manager adalah bagian dari proyek SPAN (Smart Phone Ad-Hoc Networking) yang terdiri dari Layanan MANET, modul MANET Routing Protocol, sebuah lapisan yang mengelola keamanan.

Aplikasi 'uRep' merupakan aplikasi berbasis Android yang dapat memberikan laporan berupa teks berdasarkan lokasi serta dapat melakukan pengambilan dan geotag foto menggunakan fungsi built-in GPS dari smartphone untuk melaporkan masalah kerusakan setelah terjadi bencana alam (Morreale, Goncalves \& Silva 2015). Aplikasi ini juga dapat digunakan untuk merespon laporan yang telah diberikan oleh user lain. Aplikasi 'uRep' dijalankan pada smartphone berbasis Android yang saling terhubung melalui jaringan MANET sehingga dapat digunakan untuk mengurangi waktu yang dibutuhkan untuk memulihkan layanan-layanan penting setelah terjadi bencana saat infrastruktur jaringan belum dapat dipulihkan.

\section{Metode Penelitian}

Sistem komunikasi yang dirancang terdiri beberapa perangkat android yang dapat saling berkomunikasi dengan mengirimkan pesan teks dan suara melalui jaringan wireless, perangkat android yang digunakan juga harus dapat meneruskan paket data dari perangkat lain ke perangkat yang dituju.

Pada penelitian ini digunakan empat buah smartphone android yang mendukung wireless extension (wext) untuk dijadikan bahan peneltian, yaitu:

- 3 buah Galaxy SII Epic Touch, SPH-D710

- 1 buah Galaxy Grand 2, SM-G7102

\subsection{Pengaktifan Wireless pada Android ke Mode Ad-Hoc}

Pada tahap ini dilakukan pemasangan sistem operasi dengan kernel yang mendukung perangkat wireless extension (wext) ke empat buah perangkat android yang digunakan. Untuk perangkat SPH-D710 digunakan sistem operasi android CyanogenMod 11 yang berbasis Android 4.4.4 KitKat, dan untuk perangkat SM-G7102 digunakan CyanogenMod 12.1 yang berbasis Android 5.1 Lollipop.

Pada Gambar 3 ditunjukkan perangkat SPHD710 yang sudah terinstall CyanogenMod 11 berbasis android KitKat 4.4.4 dengan versi kernel 3.0.64 dan pada Gambar 4 ditunjukkan perangkat SM-G7102 yang sudah di-install CyanogenMod 12.1 berbasis Android 5.1.1 dengan versi kernel 3.4.0. 


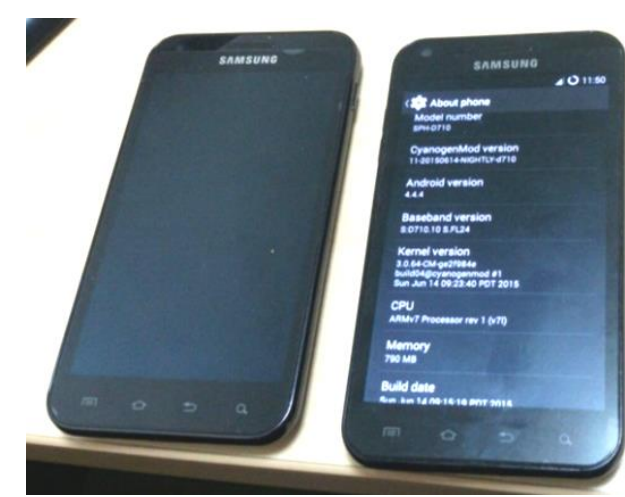

Gambar 3. Galaxy s II Epic Touch, SPH-D710

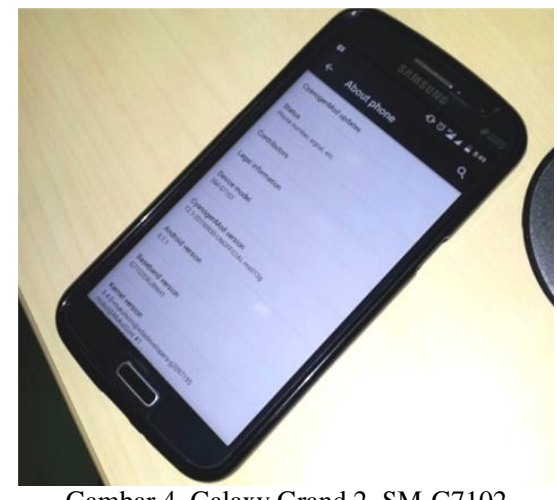

Gambar 4. Galaxy Grand 2, SM-G7102

Pemasangan Sistem Operasi Android CyanogenMod dilakukan dengan terlebih dahulu meng-install ClockWorkMod (CWM) ROM Manager Recovery terlebih dahulu, seperti yang ditunjukkan pada Gambar 5.

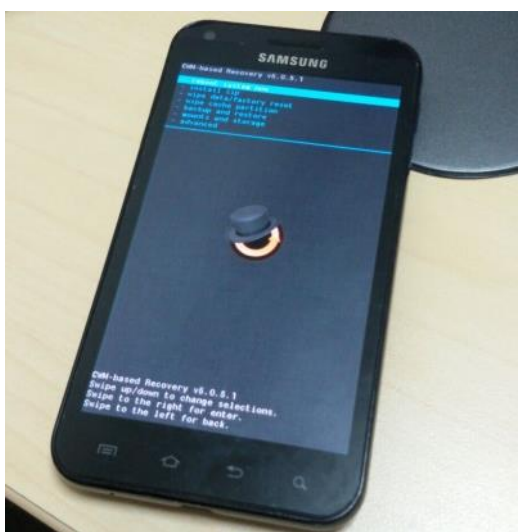

Gambar 5. ClockWorkMod (CWM) ROM Manager Recovery pada SPH-D710

Setelah CWM ROM Manager Recovery terinstall, langkah berikutnya adalah meng-install Sistem Operasi Android CyanogenMod pada perangkat SPH-D710 dan SM-G7102. Untuk menginstall Cyanogenod terlebih dahulu ROM CyanogenMod disimpan ke SDCard, lalu ROM diflash melalui CWM ROM Manager seperti yang ditunjukkan pada Gambar 6. Setelah proses flash selesai, perangkat di-boot ulang dan tunggu sampai perangkat memuat sistem operasi CyanogenMod.

Setelah proses install selesai, langkah berikutnya adalah mengaktifkan wireless $\mathrm{di}$ perangkat android ke mode Ad-Hoc. Aktifasi AdHoc pada wireless dapat dilakukan menggunakan aplikasi Manet Manager yang ditunjukkan pada Gambar 7. Aplikasi Manet Manager ini dapat diunduh melalui PlayStore.

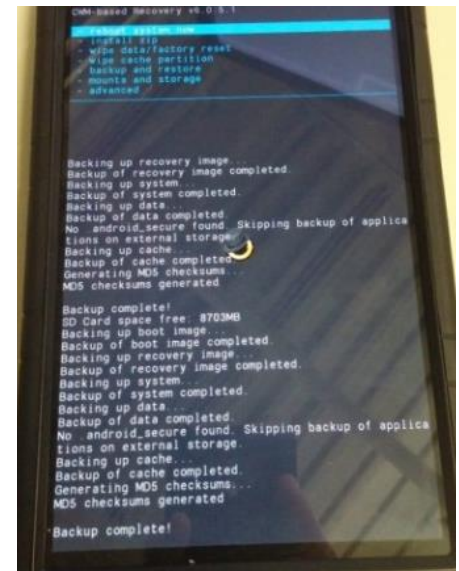

Gambar 6. Proses Flash ROM CyanogenMod melalui CWM ROM Manager.

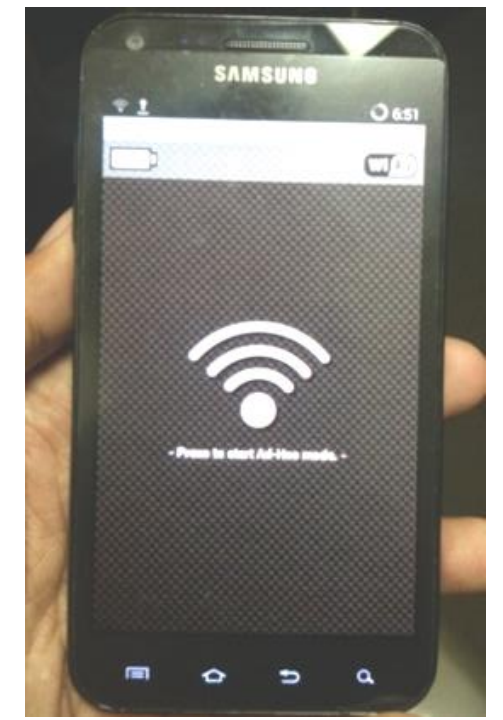

Gambar 7. Aplikasi Manet Manager untuk mengaktifkan wireless ke mode Ad-Hoc.

\subsection{Perancangan aplikasi}

Pada tahap ini dirancang antarmuka untuk aplikasi komunikasi melalui jaringan manet, aplikasi dirancang untuk bisa melakukan komunikasi berupa pesan teks yang dikirimkan dari salah satu perangkat ke seluruh perangkat yang terhubung dengan perangkat pengirim melalui jaringan manet. 
Pada Gambar 8 ditunjukkan diagram dari desain aplikasi yang dirancang untuk melakukan komunikasi pada perangkat android. Aplikasi yang dirancang bersifat peer-to-peer, dimana semua aplikasi yang berjalan memiliki tingkatan yang sama, tidak ada yang bertindak hanya sebagai server ataupun hanya sebagai client. Pada aplikasi tersebut akan dibaca posisi dari perangkat android melalui GPS. Posisi longitude dan latitude akan dibaca secara berkala dan dikirimkan secara broadcast ke seluruh perangkat yang terhubung melalui jaringan manet, sehingga seluruh perangkat yang terhubung dapat mengetahui posisi dari perangkat-perangkat yang terhubung dengannya.

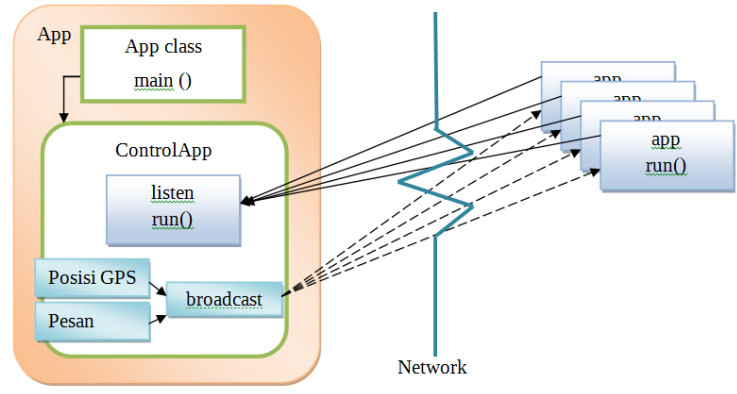

Gambar 8. Diagram dari desain aplikasi komunikasi berbasis MANET.

Pesan teks yang dikirim oleh perangkat juga dikirimkan secara broadcast menggunakan protokol transport UDP, sehingga seluruh perangkat yang terhubung dapat menerima pesan dari perangkat-perangkat yang terhubung dengannya.

\section{Pengujian dan Pembahasan}

Pengujian dilakukan dengan membuat aplikasi menggunakan Android Studio sesuai dengan rancangan yang sudah dibuat, setelah selesai dikembangkan, aplikasi di-install ke empat perangkat yang digunakan sebagai bahan penelitian.

Dalam pengujian ini dilakukan percobaan percakapan berupa pesan teks dengan aplikasi yang telah dibuat di perangkat android yang masing-masing perangkat tersebut terhubung melalui jaringan MANET. Pengujian dilakukan di gedung Universitas YARSI lantai 5 dengan denah seperti yang ditunjukkan pada Gambar 9. Jarak antara $\mathrm{A}$ dan $\mathrm{B}$ adalah 40 meter, $\mathrm{B}$ dan $\mathrm{C}$ adalah 40 meter, $C$ dan D adalah 20 meter, serta A dan C adalah 56,57 meter. Kedua jenis perangkat sudah mendukung Wi-Fi 802.11 seri “n”, dengan jarak maksimal dari jangkauan wifi adalah $50 \mathrm{~m}$.
Sehingga perangkat A hanya dapat terhubung langsung dengan perangkat $\mathrm{B}$, perangkat $\mathrm{C}$ hanya dapat terhubung langsung dengan perangkat $\mathrm{B}$ serta perangkat $\mathrm{B}$ dapat terhubung langsung dengan perangkat $\mathrm{A}$ dan $\mathrm{C}$.

Pada pengujian sistem, dilakukan pengiriman pesan dari satu perangkat ke semua perangkat. Pada hasil pengujian, pesan dari A dapat sampai ke perangkat B, C dan D pada saat jarak antara perangkat $A$ dan $C$ berada di jangkauan perangkat $\mathrm{B}$, serta perangkat $\mathrm{D}$ berada pada jangkauan perangkat $\mathrm{C}$ seperti yang ditunjukkan pada Gambar 10, Gambar 11, dan Gambar 12, yaitu dengan jarak maksimal 50 meter.

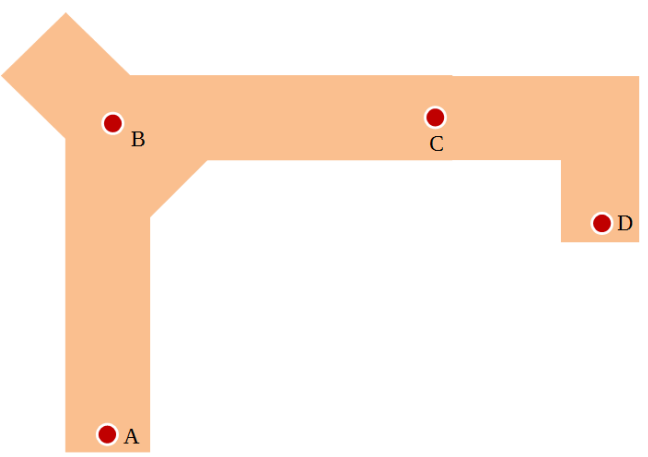

Gambar 9. Denah tempat pengujian dan posisi tiga buah perangkat yang digunakan untuk pengujian.

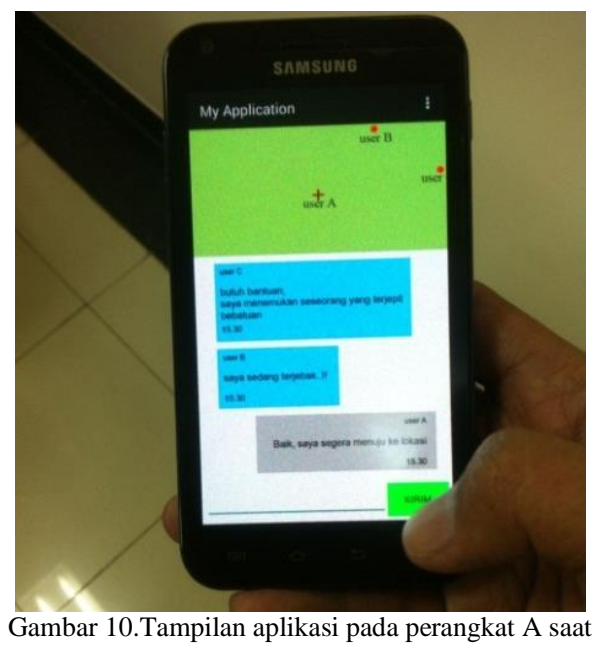
berkomunikasi dengan perangkat $\mathrm{B}$ dan $\mathrm{C}$ 


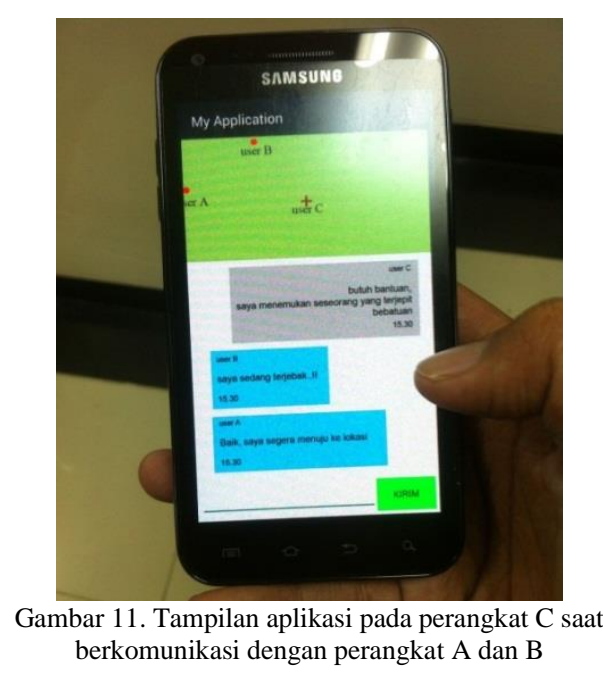

Dari hasil pengujian yang didapatkan, sistem yang dikembangkan dapat digunakan untuk mengirimkan pesan teks ke beberapa perangkat yang tehubung melalui wifi tanpa membutuhkan perangkat infrastruktur jaringan, sehingga sistem ini dapat digunakan pada penanggulangan bencana yang mengakibatkan lumpuhnya sarana dan infrastruktur jaringan dan komunikasi.

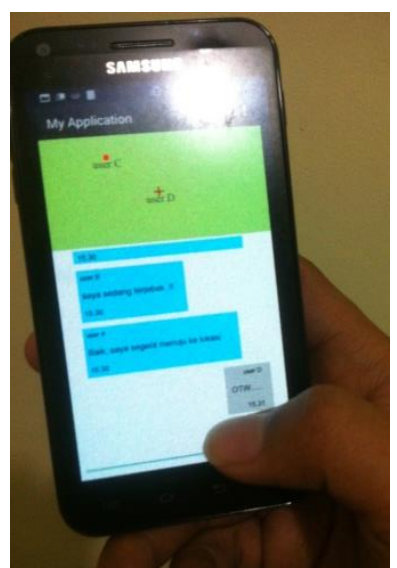

Gambar 12. Tampilan aplikasi pada perangkat D saat berkomunikasi dengan perangkat A dan B

Aplikasi yang dikembangkan pada penelitian ini menggunakan protokol UDP di lapisan transport untuk mengirimkan paket data berupa pesan teks, sehingga jika pada saat pengiriman terjadi kerusakan data atau jarak dari perangkat melampaui batas jangkauan wifi, maka pesan akan di-drop dan pesan tersebut tidak akan pernah sampai.

Untuk dapat meningkatkan kinerja dari sistem komunikasi ini, perlu dikembangkan kembali aplikasi dengan fitur yang lebih diperuntukkan untuk kebutuhan penanggulangan bencana.

Agar sistem komunikasi dapat digunakan untuk jangkauan yang lebih jauh, perlu dilakukan pengujian dengan menambahkan router tambahan di beberapa titik yang difungsikan sebagai mesh .

\section{Kesimpulan}

Pada penelitian ini telah dibuat aplikasi untuk saling berkomunikasi pada perangkat android berbasis jaringan MANET yang tidak membutuhkan infrastruktur jaringan agar bisa digunakan pada penanggulangan daerah bencana yang menghancurkan seluruh sarana dan prasarana komunikasi.

\section{DAFTAR PUSTAKA}

bluAir 2011, Bluetooth Range, viewed 12 Januari 2014, http://www.bluair.pl/bluetooth-range.

Catarci, T, de Leoni, M, Marrella, A, Mecella, M, Salvatore, B, Vetere, G, Dustdar, S, Juszczyk, L, Manzoor, A \& Truong, H-L 2008, 'Pervasive Software Environments for Supporting Disaster Responses' IEEE Internet Computing, vol. 12, no. 1, pp. 26-37.

Ducatelle, F 2007, 'Adaptive Routing in Ad Hoc Wireless Multi-hop Networks', PhD thesis, Faculty of Informatics, Universita della Svizzera italiana, Lugano, Switzerland.

Ducatelle, F, Di Caro, G A \& Gambardella, L M 2010, Routing in urban mobile ad hoc networks, Wiley-iSTE.

HPLI 2012, Potensi Bencana, viewed 10 Januari 2015, http://www.hpli.org/bencana.php.

Morreale, P A, Goncalves \& Silva, C 2015. 'Mobile ad hoc network communication for disaster recovery', International Journal of Space-Based and Situated Computing, vol. 5, no. 3, pp. 178-186.

Muliawati, T H, Nadhori, I Z \& Setiowati, Y 2011, 'Aplikasi Pengiriman Pesan Secara Berantai pada Daerah Bencana Terisolasi Menggunakan Teknologi Manet', viewed 10 Januari 2014, http://repo.eepisits.edu/1093/1/makalah.pdf.

Perkins, C E \& Bhagwat, P 1994. 'Highly dynamic destination-sequenced distancevector routing (DSDV) for mobile computers', ACM SIG-COMM'94 Conference on Communications Architectures, Protocols and Applications, pp. 234-244.

Perkins, C E \& Royer, E M 1999, 'Ad-hoc ondemand distance vector routing', In Proceedings of the Second IEEE Workshop on Mobile Computing Systems and Applications, pp. 90-100. 
Royer, E M \& Toh, C A 1999, 'A review of current routing protocols for ad -hoc mobile wireless networks', IEEE Personal Communication, vol.6, no. 2, pp. 46- 55.

Stoker 2012, The Span Project, viewed 20 Januari 2014, https://github.com/ProjectSPAN.
The Serval Project 2013, Mesh Routing, viewed 15 Januari 2014, http://developer.servalproject.org/dokuwiki/do ku.php?id=content:tech:mesh_routing.

Tornow, J D 1987, 'The DARPA Packet Radio Network Protocols', Proceedings of the IEEE, vol. 75, pp. 21-32. 